\title{
For the love and respect of the service: Applied aesthetics and palliative care
}

\author{
Marcia Brennan \\ Department of Religious Studies, Rice University, Houston, Texas, USA \\ Email: mbrennan@rice.edu
}

Received 14 August 2013; revised 5 September 2013; accepted 12 September 2013

Copyright (C) 2013 Marcia Brennan. This is an open access article distributed under the Creative Commons Attribution License, which permits unrestricted use, distribution, and reproduction in any medium, provided the original work is properly cited.

\begin{abstract}
In this article, the author discusses her experiences as an artist in residence in the Department of Palliative Care and Rehabilitation Medicine at the University of Texas M. D. Anderson Cancer Center. Emphasis is placed on applied aesthetics in palliative care and their implications for addressing communication, spiritual, and health care issues for military service members. Drawing on six vivid case studies, the author examines the various ways in which end of life narratives can shed valuable light on key issues concerning individuals' life experiences in the Navy, the Army, and the Air Force. These cherished images strengthened people's spirits at the end of life, and each of the men told their stories with pride.
\end{abstract}

Keywords: Palliative Medicine; End of Life; Psychosocial Oncology; Aesthetics; Communication; Spirituality

\section{INTRODUCTION}

Since March of 2009, it has been my great privilege to serve as an artist in residence in the Department of Palliative Care and Rehabilitation Medicine at the University of Texas M. D. Anderson Cancer Center. In my “day job”, I am an associate professor of art history and religious studies at Rice University in Houston, Texas, where my research areas include modern and contemporary art history and museum studies, comparative mysticism, and the medical humanities. Despite the differences between my research fields, each of these areas shares a common set of themes and challenges, namely: how do we find a language to describe states of being for which there is no language? How do we represent the unrepresentable and translate the untranslatable? How do we formulate metaphors of transience to describe subjects that are simultaneously coming into form and going out of form, sometimes within the framework of a single image? And how do we represent the fragile zones of contingency that mark both gradual transitions as well as more dramatic shifts between states of being? Notably, these issues are as pertinent to theoretical discussions of abstract painting's simultaneously dissolving and crystallizing structures as they are in the contemplation of spiritual experience and mystical ecstasy, as they are in the very real challenges of people at the end of life. Thus, throughout all of my work I am fascinated-and profoundly moved-by subjects and situations that repeatedly exceed our capacity to represent them, even as we repeatedly attempt to do so, often through imagery that conveys transitional states and transformational visions $[1,2]^{1}$.

At M. D. Anderson, my work is sponsored by COLLAGE: The Art for Cancer Network, a non-profit organization conceived and founded by Dr. Jennifer Wheler. Working on both the Acute Palliative Care Inpatient Unit and the Palliative Care Outpatient Clinic, I assist patients and their caregivers in constructing meaningful narratives to express their insights and experiences. Thus I primarily serve as a translator, yet much of what I translate is ineffable. I create a context, and provide critical skills, so that people facing extraordinarily difficult life situations have an opportunity for personal and symbolic expression, which then becomes clothed in aesthetic form.

As an artist in residence, I constantly confront the challenge of creating human connections across a formidable gulf of separation. Frequently, when I initially approach a patient, I am told that the work "sounds interesting, but I have no artistic ability”. This invites me to

\footnotetext{
${ }^{1}$ This article represents part of a larger project in which I focus on creative expressions at the end of life. The texts range from a scholarly book on aesthetics and psychosocial oncology, entitled Words Beyond Words: Finding Language at the End of Life (forthcoming from Intellect Books, UK), to a personal discussion of the mystical and artistic dimensions of my end of life work in The Angels In Between: The Book of Muse (Winchester, UK: Axis Mundi Books, 2013).
} 
respond, "Well, let's just say for a moment that you did have artistic ability. What images would you want to write about?” Depending on the circumstances I might also ask, "Where are you from? What do you love to do?", or even more simply (yet never simply), "What do you love?" Sometimes I'll just ask people directly, "If you had an image in your mind of something that holds special meaning for you —and it can be anything at allwhat would that be?" Very often a flash of illumination will become visible on the person's face, and they will share an image with me. They will describe a subject or a scene, while I gently encourage them to talk and make notes to help crystallize their thoughts. Once the artwork is complete, I read the person's words back to them, while making any additions or corrections that they indicate. The narrative is then inscribed into a handmade paper journal, which the person is able to keep and share with their family, either as a medium for further creative expression or as a legacy gift that performs a memorial function. The portable microenvironment of the text thus provides a durable yet tender memory of this transient moment in their lives.

Beyond this brief initial description, there is not an established protocol or predetermined procedure for our interactions $[3]^{2}$. Instead, I have found that the opposite approach works best, as this creative practice requires a significant degree of self-overcoming. People come from all over the world, as well as from half a mile down the road, seeking treatment at M. D. Anderson. Not only are each person and each situation unique, but at the end of life dramatic physical and emotional changes can occur almost immediately. Thus it is necessary to exercise subtle discernment and to practice the art of allowance while stepping lightly, speaking softly, and meeting everyone's gaze directly so as to see the person and not the illness.

In this article I present six stories that feature vivid descriptions of people's experiences in the military, including the Navy, the Army, and the Air Force. At the end of life, these cherished images promoted communication and strengthened people's spirits, and each of the men told their stories with pride.

\section{NAVY}

\section{For the Love and Respect of the Service: The Navy Uniforms}

"Would you please go in and work with this man? He

\footnotetext{
${ }^{2}$ Notably, artists in residence are neither therapists nor art therapists. While the patient interactions often contain important psychodynamic insights and revelations, these activities represent not a therapy, but a critical intervention that broadly allows for the expression of personal uniqueness. Regarding some of the overlapping psychosocial and support functions that artistic activities can provide within an interdisciplinary team, see the section on "Art Therapy" in Max Watson et al., Oxford Handbook of Palliative Care, $2^{\text {nd }}$ ed. (Oxford: Oxford University Press, 2009), pp. 803-804.
}

has no family anywhere in the area, and he's sitting all alone in his room, writing."

By the time this visit occurred, I knew very well that the nurse's brief description could mean just about anything. As always, I approached the man's room while remaining open to the open. I knocked gently on the door, introduced myself, and asked if I could visit with him for a few moments. All of which is to say that I walked into this man's room with absolutely no expectations. Yet within a short while, an intricate story was emerging. I asked the man where he was from, and to our mutual surprise, we discovered that we had much in common. This man originally came from New York, although he had left in the late nineteen fifties (I was born nearby in Connecticut in the mid-nineteen sixties). We also found that we shared the same mixed ethnic heritage on both sides of our families. Now we sat together, so many decades later and thousands of miles away, in his hospital room at M. D. Anderson.

This man's artwork centered on the male relatives of his family and their strong connection to the Navy, a tradition that extended from his grandfather to his father, his uncles, himself, and his son. This older man was also a war veteran who was very tough and grounded in his perspective. So it was all the more surprising when he shared a story of supernatural appearances. This man told me that, when he was a young man, his deceased grandfather and father came to him at a critical juncture in his life. Now the memory of their presences was returning to him at the end of his life, another crucial moment of transition. His story is entitled:

For The Love And Respect Of The Service:

The Navy Uniforms ${ }^{3}$

For my image,

I go to my son and my family.

I include all of them,

Because we have stayed together

Through all the problems

And not gone our separate ways.

First, I need to tell you that the name James

Is sort of sacred in our family.

My grandfather was James, Senior.

His son, my uncle, was James, Junior.

And I'm Robert James.

The best thing I can say about my family

Is that there is one night I've never forgotten.

Once a week, the whole family showed up

At my grandmother's house

To have a meal together.

${ }^{3}$ All names have been changed to preserve the privacy of the individuals involved. 
We ate in the dining room,

And we were a large family.

But the two chairs at the head of the table

That were my grandfather's chair

And my father's chair

Were always left empty after they passed away.

That night, I was just getting ready to sit down and eat When one of my uncles turned to another uncle

And said, in a loud voice,

"What are we going to do about this boy?"

I had just joined the Navy earlier that week,

But I hadn't told anyone.

As soon as my uncle said those words

I looked up from my chair

And I saw my Granddad in his Navy uniform,

And I saw my Dad in his Navy uniform.

They had both been dead for years,

But they were sitting there at the table

In their Navy uniforms.

And then I saw my two uncles,

Who were in street clothes,

Wearing their Navy uniforms.

\section{I knew I had to join the service}

Because of the love and respect I had for these men,

And the love and respect they had for the service.

And I knew that, if I didn't join the service,

I could never sit down with them at that table again.

After I read these tender and powerful words aloud, this man and I held hands for a few minutes. He was very grateful for the visit, and he particularly appreciated the handmade journal, because he said that he had some more experiences he wanted to record.

Reflecting these themes, the West Coast visual artist Lyn Smallwood has created a drawing set in an ItalianAmerican home in New York during the late nineteen fifties (Figure 1). Delicately rendered in graphite on Arches paper, the drawing's atmosphere is soft and intimate as an extended family sits down together at a long, formal dining room table. Much like in traditional homes of this era, two wooden colonnades flank the outer edges of the high-ceilinged dining room, while in the room beyond, a sideboard holds assorted china. This drawing is presented from the perspective of someone who has just entered the dining room through the open doorway that leads in from the kitchen. The tip of the dining room chandelier glows brightly overhead and provides a source of emphasis and contrast that opens and illuminates the scene. The chandelier also centers the composition visually as it establishes a direct linear pathway extending through the middle of the long dining room table.

${ }^{4}$ For an extended discussion of the historical imagery associated with death and dying, see Philippe Ariès, Images of Man and Death, Trans. Janet Lloyd (Cambridge: Harvard University Press, 1985).

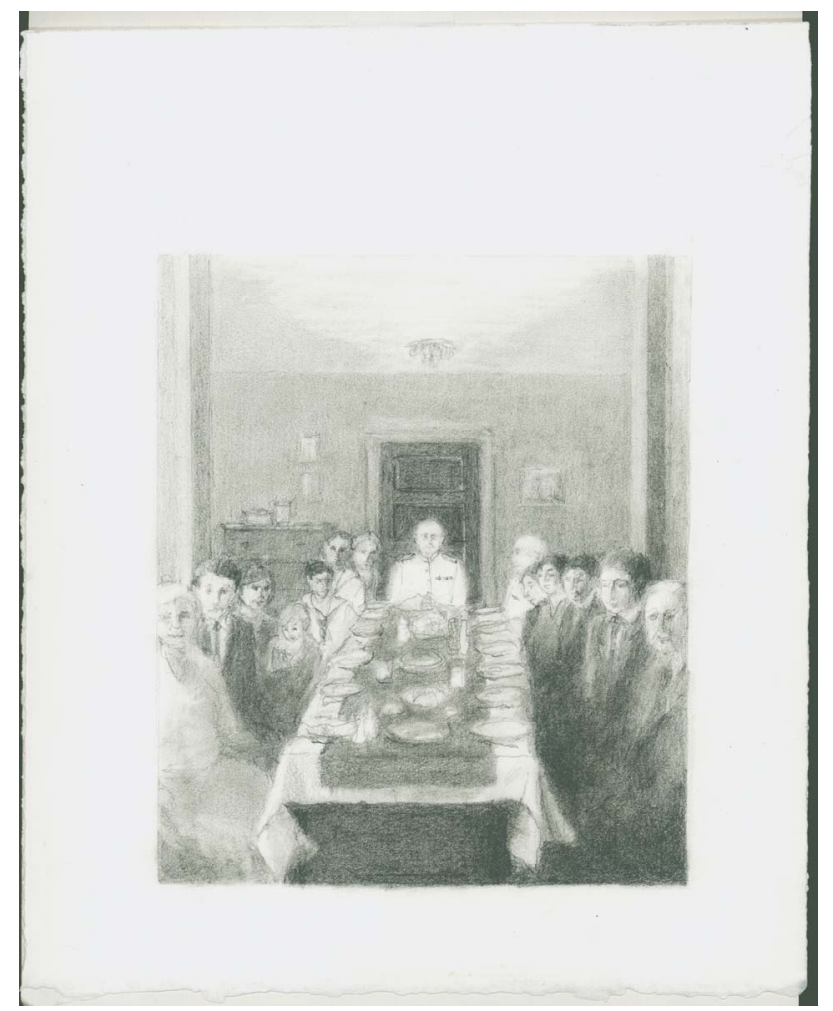

Figure 1. Lyn Smallwood, The Navy Uniforms, 2013, graphite on Arches paper.

This primary sight line ultimately leads to the dark wooden door that frames the grandfather's luminous presence at the head of the table $[4]^{4}$.

In this multi-figure composition, the dining room table appears symbolically like an extended family tree. It's as though one of the man's uncles has just loudly asked, "What are we going to do about this boy?" and gestured down the table toward his nephew, while the family looks up and over at him. In turn, the young man himself has also just looked up from his seat at the foot of the table to see his grandfather and father in their Navy uniforms. His grandmother is seated in her customary place at her husband's side. Next to her are the man's two uncles, followed by family members of all ages, ranging from elderly people to very young children. Everyone is dressed formally for Sunday dinner. The two younger uncles wear sailor's white middy shirts, while the grandfather and father are senior presences dressed in the suits of Navy officers, with decorations on their chests. The scene culminates in the bright glow of their Navy uniforms, an etheric vision that stayed with this man for the rest of his life $[5]^{5}$.

Notably, The Navy Uniforms contains highly concrete and detailed imagery that combines an intensity of visu-

\footnotetext{
${ }^{5}$ Regarding the phenomena of supernatural appearances at the end of life, see especially Peter and Elizabeth Fenwick, The Art of Dying: A Journey to Elsewhere (London: Continuum, 2008).
} 
alization with emotional poignancy and spiritual insight. Taken together, these elements create a sense of suspended temporality-a lucid state where time seems to stand still—and this quality is as compelling as it is heart opening. In turn, this man's narrative engages many different states of being. The story begins with the immediate physical context of an older man sitting alone in his hospital room at the end of life. Our visit together opens up a youthful memory of the time when he first joined the Navy, and his grandfather and father appeared to him in spirit form. Often during the production of an artwork, a person will begin in one state of mind and body, and they will experience additional states of being as the visit unfolds. When the artwork is complete, the person returns to their physical surroundings in a slightly altered form, one that is more uplifted. These transitions can help to renew the spirit and perspective of the person at the end of life. As we work together, I have often witnessed people enter into a profound state of peace, to unclench their hands, to uncurl their bodies from a fetal position, and to stop trembling. It's as though the person's subtle bodily memories and experiences help to strengthen and transform their current physical condition and bring them to a more elevated place inside of themselves.

At the same time, these uplifted states are often associated with narratives that are extremely concrete and sensual. Much like this man's story of his grandmother's dining room table, end of life narratives are frequently extremely visual, aural, and tactile, just as they can engage a strong sense of taste and smell. Deep bodily memory seems to be both sensitive and etheric, and it appears to inhabit a state of consciousness that is parallel to the time and place in which the person is actually living. Along these lines, I have also frequently observed that, at the end of life, a person's surroundings can become extremely constrained as the world appears to shrink before their eyes. Yet in these very limited circumstances, seemingly little things can become monumental. As a different perspective emerges, so too does an altered sense of scale and proportion, and in this state bodily memories and experiences are not constrained by the familiar parameters of time and space. Thus paradoxically, at the end of life there can be an expansiveness of vision that recognizes the large within the small, the numinous within the ordinary, and the past and the future contained within the fullness of the present.

\section{ARMY}

\subsection{The Edge Blade}

One day I visited with a middle-aged man whose metastatic renal cell cancer had spread throughout his abdomen. He was enrolled in a Phase One clinical trial, and he was on the palliative ward receiving supportive care for pain control. This man had spent several years in the Army, where he worked as a mechanical engineer. As he told me, "I enjoy designing things and seeing them come off of the paper and into life. That's pretty gratifying." After chatting briefly about his professional work, I asked the man about his imagery. At first he was a bit reticent, but after a moment he shared a powerful, metaphorically resonant story about his father and his career in the Army. These images visibly brought this man strength at this difficult moment in his life:

The Edge Blade

My image is of this little pocket knife

That my dad used to keep out in the back shed.

He always stuck it in a piece of wood

That he whittled.

If I ever needed an edge blade,

I knew I could find one there.

When I think of home,

I think of that.

My dad was a big, burly guy, And he's the reason I joined the military.

I always looked up to my dad.

\subsection{The Emblem of a Career Army Soldier}

Another day I met with an older man who was at the very end of his life. While he was now retired, the bulk of his multi-decade career was spent in the Army, and he had served in Viet Nam. Although it was difficult for him to talk, we were able to visit briefly. When I asked him about his cherished images, he briefly replied, "A soldier. One who comes and goes." He then told me that he was in the military for several years, and "I was on the outside as well, but then I went back into the military. I'm mostly career Army." This man had served as a noncommissioned officer and his artwork told the story of "The Emblem of a Career Army Soldier".

After a few minutes his wife returned to the room, and I presented her with her husband's words. She was so grateful, and she said that the artwork was "a gift of gold". The couple's adult son was also quite moved, and he shook my hand firmly, twice. Later that evening, this man passed away peacefully at M. D. Anderson.

\subsection{I'm a Fighter}

Another day I met a middle-aged man who suffered from an aggressive Stage 4 sarcoma with pronounced lymphedema on one side of his body. Yet perhaps most striking of all was that, despite the extreme pain and disfigurement of his illness, this man continued to see and describe himself as a warrior. As we visited he told me 
that he loved sports, especially basketball and football, and that he had played football in college. I asked him where he went to school and he told me that he went to West Point. To our mutual surprise, we discovered that we knew some people in common. This experience was very moving, and at the end of our visit this brave man told me to be strong and to pray for him. As he said:

I'm A Fighter

Cancer is a fight,

And I'm a fighter.

I love sports,

And I played football in college.

At West Point, I played on the defensive line.

I've had cancer for a few years now.

They thought they had caught it,

But it came back,

Which means that it is really aggressive.

I should probably be more wary and upset,

But I feel patient and good.

I believe God has sent me here.

If my time is up,

I'm willing to go.

I'm a devout Christian,

And I'm a fighter.

I'll fight it to the end.

Whatever it takes, I'm going to do.

I told this to my doctor,

Because he's a fighter, too.

\subsection{Do You Mind If I Fly This Thing?}

When I first entered this man's room, his wife and his friend were at his bedside. When I introduced myself and asked if he would like to visit with me, the man considered the question carefully and he almost said no. But then he decided that this was important, so his wife and his friend "stepped out to get a Coke". Afterward, he told me that he was really glad that he decided to do the artwork.

We ended up having a lengthy, wonderful visit. It wasn't until afterward that I learned from the attending physician and the chaplain that control was a major issue for this man, and that up to this point, he had resisted opening up and talking to anyone. Yet frankly, once he started talking, it was difficult to get him to stop. There were various interruptions during our visit as the phone rang several times, and members of the nursing staff came in to do some procedures, but our exchange was too precious for the man to stop talking. In short, this man needed to be heard and to express himself in this way.
He had spent several years in the Army, and he had also served in Viet Nam. As he told me, flying was the most fantastic experience in his life. Being a pilot gave him a sense of freedom and power that he truly loved and missed very much, particularly now that he was confined to bed with Stage 4 metastatic cancer and investigating hospice options.

This man spoke softly with a gentle southern accent, yet a few times during our visit, his voice notably changed. This first happened when he told me about the time his "Battalion Commander chewed us out royally for my doing something I wasn't supposed to be doingflying illegally”. At another point, he described being a pilot and giving orders to his crew. As he did so, his voice changed and it was as though he was speaking to a subordinate soldier, and I could feel the power of command go through him.

In addition to these themes, his artwork provided a means for this man to express his spiritual insights and visions, and his language centered on the leitmotif of flight:

Do You Mind If I Fly This Thing?

When I was a boy,

I would look up at the sky and see a plane,

And I thought, "One of these days,

I'm going to fly one of those things."

I've been flying ever since I could.

I was in college, and they offered me

A ground school course,

And I thought, "That sounds interesting."

Time progressed, and along came Viet Nam.

I went into the Army,

And I got assigned to the Artillery.

Part of my job had to do with flying.

My pilot was a captain, and a good pilot.

I was a junior lieutenant

And a Forward Observer, an F. O.

Then I passed my test and got my pilot's license.

One day, over the intercom I asked him,

"Do you mind if I fly this thing?"

And he said, "Are you a pilot?"

I said, "Yes," and he said,

"Okay. How about the next time we're ready to go up,

I'll show you how to put the stick in

And how to pull the pedals up."

He showed me, and I got the idea

As we went upstairs in a J3 Cub.

With flying, there's physical power, And there's horse power.

When you're up there,

It's just fantastic. 
You can get an image of God

From the beauty you see as a pilot.

On a clear, steel blue day-

Yes, you can get it all from that.

\section{AIR FORCE}

\section{We Supported Each Other, Top to Bottom}

Another day I visited with a man who had spent his career as an Air Force pilot, and who was leaving the hospital later that day with hospice. He was a young man with several visitors in his room, so I was a bit surprised when he immediately said yes, he would like to produce an artwork together. Much like the man whose story appears above, this man also began our conversation by telling me, "I can remember that I've always wanted to fly. I love the sky, and the sea." While he was laconic and reserved, he did tell me about his experiences flying combat missions over Afghanistan, and the spirit he felt while working with his crew:

We Supported Each Other, Top To Bottom

\section{I can remember}

That I always wanted to fly.

I got a chance to go to the Air Force Academy,

And I've got an active duty commission,

And a pilot's commission.

Flying is what I've always wanted to do,

And what I like doing.

That's been the nicest thing,

The ability to do all that flying.

I was flying T-38s

And then I got into heavy C130s.

I've been flying up there

With a crew over Afghanistan.

When everything is in synch,

And everybody just knows where to go,

You don't need to say anything.

We're all doing our job,

And doing it well.

I was an Air Craft Commander,

So it all began and ended with me.

If they were on my crew,

Then we supported each other

\section{Top to bottom.}

${ }^{6}$ For extended discussions of the end of life in our contemporary culture see James W. Green, Beyond the Good Death: The Anthropology of Modern Dying (Philadelphia: University of Pennsylvania Press, 2008); and Allan Kellehear, ed., The Study of Dying: From Autonomy to Transformation (Cambridge: Cambridge University Press, 2009).

${ }^{7}$ Regarding the ways in which death can shed light on the intrinsic uniqueness of human beings, see Jacques Derrida, The Gift of Death, Trans. David Wills. $2^{\text {nd }}$ ed. (Chicago: University of Chicago Press, 2008).

\section{CONCLUDING DISCUSSION}

This article demonstrates the various ways in which applied aesthetics can help to provide comfort and clarity to patients and family members during key moments of transition $[6,7]^{6}$. Notably, the production of the artworks can significantly enhance an individual's creative and spiritual self-expression, and promote personal and group communication at the end of life $[8]^{7}$. Such artistic interactions have the potential to engage deep bodily memory and to evoke poignant subjective associations, which in turn can help to renew the spirit and perspective of people at the end of life and their caregivers.

In particular, the stories presented in this article exemplify the power of aesthetics to provide a common meeting ground by making concrete representations of the extraordinary - and often highly elusive - states of consciousness and spiritual insight that can, and do, arise at the end of life. By expressing these inner states outwardly, the artworks can help to facilitate communication and promote a sense of mutual understanding between the person and the world around them. Without such a tangible mode of expression, these inner visions might otherwise remain invisible. In addition, this creative modality of expression may provide an instrumental means to help relieve pain. Once, after I presented my work at a scholarly talk in the Texas Medical Center, a senior palliative care physician made an extremely generous comment. He remarked that, in all of his years of providing palliative care, he has found that he can write a prescription to alleviate pain, but that he can't write a similar prescription to relieve suffering. This presentation showed him how the work of the Artist In Residence can help to address human suffering, which in turn can help to ease pain $[9]^{8}$.

In the extremely challenging circumstances of end of life care, preserving the integrity of personal identity amidst the fragmentation of terminal illness itself represents a type of heroism. In this context, the artist per-

\footnotetext{
${ }^{8}$ Regarding the connection between human suffering and various types of pain, Dame Cecily Saunders, the founder of the modern hospice movement who pioneered the treatment of pain for dying patients, specifically identified four distinct types of pain that people encounter at the end of life. They include not only the physical pain of the body, but the social pain of financial and cultural crises, the emotional pain associated with feelings of helplessness and isolation, and the spiritual pain that arises from the need to feel safety and find meaning in life. Each of these factors represents a dimension of what Saunders termed "total pain”. As Saunders observed: "It isn't enough to treat the physical pain alone, although this is important. The whole person is suffering so the whole person must be treated" so that care "can reach the most hidden places”. See Cicely Saunders, "Other components of total pain” in Living with Dying: A Guide to Palliative Care, $3^{\text {rd }}$ ed. (Oxford: Oxford University Press, 1995), pp. 45-58. Notably, Saunders ends this book with a discussion of the pain experienced by the medical staff and the corresponding need for support at the professional level. In my own academic work, I reflect on the various ways in which the humanities can contribute to addressing human suffering within a medical context which, in turn, can help to shape an overall model of care.
} 
forms something like a witness function, a critical affirmation in which people tell me their stories so that there can be a surfacing to consciousness of something that is often lying just below the conscious level. People tell me, so that they can tell themselves, through the words and images that surface to the surface at the end of life. As I noted at the beginning, these powerful images strengthened these men's spirits, and at the end of life, each man told his story with pride.

\section{REFERENCES}

[1] Brennan, M. (2013) The angels in between: The book of muse. Axis Mundi Books, Winchester.

[2] Brennan, M. (in Press) Words beyond words: Finding language at the end of life. Intellect Books, Bristol.

[3] Watson, M., Lucas, C., Hoy, A. and Wells, J. (2009) Ox-

\section{A NOTE ON THE TEXT}

The accompanying illustration was commissioned from the West Coast visual artist Lyn Smallwood. The artwork was not produced in situ at the patient's bedside, or from a photograph or any other type of derivative material. The image contains no recognizable likeness that bears any resemblance to any individual with whom I have worked, nor does the illustration resemble any artworks now in the possession of surviving family members. The artwork thus complies with the standards associated with patient privacy and confidentiality. In addition, this project has been favorably reviewed by two independent Institutional Review Boards (IRBs) at Rice University and at the M. D. Anderson Cancer Center. Notably, the subjects of this project are universal, human, and deeply important; as such, they raise a host of compelling issues regarding subjectivity, sensitivity, visibility, representation, and compassion that must be processed within our culture. At the same time, due to privacy concerns, the narratives presented here are abstracted sketches that are intended to be generic and anonymous. Particular identi- ford handbook of palliative care. 2nd Edition, Oxford University Press, Oxford. http://dx.doi.org/10.1093/med/9780199234356.001.0001

[4] Ariès, P. (1985) Images of man and death. Lloyd, J., Trans., Harvard University Press, Cambridge.

[5] Fenwick, P. and Fenwick, E. (2008) The art of dying: A journey to elsewhere. Continuum, London.

[6] Green, J. (2008) Beyond the good death: The Anthropology of modern dying. University of Pennsylvania Press, Philadelphia.

[7] Kellehear, A. (2009) The study of dying: From autonomy to transformation. Cambridge University Press, Cambridge.

[8] Derrida, J. (2008) The gift of death. Wills, D., Trans., 2nd Edition, University of Chicago Press, Chicago.

[9] Saunders, C. (1995) Living with dying: A guide to palliative care. 3rd Edition, Oxford University Press, Oxford. fying details relating to specific individuals have been omitted or altered, thereby assuring HIPPA compliance and preserving issues of confidentiality, particularly as specified under "The Privacy Rule”, The Belmont Report, and the Department of Health and Human Services Office for Human Research Protections, including The Common Rule and subparts B, C, and D of the Health and Human Service specifications as outlined in the Code of Federal Regulations (CFR) at 45 CFR 164 and 165 , which specifies the "safe harbor" method of deidentification. As noted above, all names have been changed to preserve the privacy of the individuals involved. Finally, it should be emphasized that the artworks are not presented as sentimentalized fictions intended to romanticize the end of life or to support a larger cultural narrative regarding what it might mean to "die a good death". Some of the stories represent condensations of two or more patient encounters in which closely related narratives emerged during the visits. All of the events I describe actually occurred and the words are the patients' own. 